\title{
One-step steam pyrolysis for the production of mesoporous biochar from oil palm frond to effectively remove phenol in facultatively treated palm oil mill effluent
}

\begin{abstract}
Conventional aerobic treatment of facultatively treated palm oil mill effluent (POME) containing phenolic compounds such as phenol, encounters difficulty because of microbial inhibition. In this study, adsorption of phenol in facultatively treated POME was proposed as a solution for mitigating the inhibition. Low-cost biochars produced from oil palm frond using nitrogen or steam pyrolysis at $600{ }^{\circ} \mathrm{C}$ were characterized and investigated for efficient and effective removal of phenol. Nitrogen and steam pyrolysis yielded mesoporous biochars with Brunauer-Emmett-Teller surface area of $368.4 \mathrm{~m} 2 / \mathrm{g}$ and $461.3 \mathrm{~m} 2 / \mathrm{g}$ respectively. Within $8 \mathrm{~h}$, steam-derived biochar attained equilibrium capacity of $59.6 \mathrm{mg} / \mathrm{L}$ in distilled water, which decreased to $18.5 \mathrm{mg} / \mathrm{L}$ in facultatively treated POME. Steam-derived biochar exhibited slightly higher adsorption capacity for phenol in facultatively treated POME due to higher surface area, wider nanopore size distribution, a larger volume of mesopores and a stronger affinity for phenol. More than $90 \%$ of phenol was removed using 16-20 g/L dosage, yielding a facultatively treated POME with $0 \%$ inhibition to aerobic microbial growth. Overall, lowcost biochar produced from oil palm frond can be used as an efficient and effective adsorbent for adsorbing phenol in facultatively treated POME to enhance the performance of aerobic treatment system.
\end{abstract}

Keyword: Oil palm frond; Biochar; Facultatively treated palm oil mill effluent; Phenol 